\title{
Transcatheter aortic valve resection: new mechanical devices
}

\author{
Huangdong Dai ${ }^{1,2 \#}$, Georg Lutter ${ }^{1,3 \#}$, Derk Frank ${ }^{4}$, Sandra Freitag-Wolf ${ }^{5}$, Ayça Topal ${ }^{1}$, Assad Haneya ${ }^{3}$, \\ Janarthanan Sathananthan ${ }^{6,7}$, Thomas Puehler ${ }^{1,3}$
}

${ }^{1}$ Department of Experimental Cardiac Surgery and Heart Valve Replacement, University Hospital Schleswig-Holstein, Campus Kiel, Germany; ${ }^{2}$ Department of Cardiac Surgery, Shanghai Chest Hospital, Shanghai Jiaotong University, Shanghai, China; ${ }^{3}$ Department of Cardiovascular Surgery, University Hospital Schleswig-Holstein, Campus Kiel, Germany; ${ }^{4}$ Department of Cardiology and Angiology, University Hospital SchleswigHolstein, Campus Kiel, Germany; ${ }^{5}$ Institute of Medical Informatics and Statistics, University Hospital Schleswig-Holstein, Kiel, Germany; ${ }^{6}$ Centre for Heart Valve Innovation, St Paul's Hospital, University of British Columbia, Vancouver, Canada; ${ }^{7}$ ViVitro Labs Inc., Victoria, Canada Contributions: (I) Conception and design: H Dai, G Lutter, T Puehler; (II) Administrative support: A Topal, A Haneya, D Frank; (III) Provision of study materials or patients: A Topal; (IV) Collection and assembly of data: H Dai; (V) Data analysis and interpretation: H Dai, G Lutter, T Puehler, S Freitag-Wolf, J Sathananthan; (VI) Manuscript writing: All authors; (VII) Final approval of manuscript: All authors.

"These authors contributed equally to this work.

Correspondence to: Thomas Puehler, MD. Department of Cardiovascular Surgery, University Hospital Schleswig-Holstein, Campus Kiel, ArnoldHeller Strasse 3, D-24105 Kiel, Germany. Email: thomas.puehler@uksh.de.

\begin{abstract}
Background: To improve periprocedural outcomes of transcatheter aortic valve implantation (TAVI), transcatheter mechanical resection devices were tested for prior ablation of the aortic cusps.

Methods: Three mechanical transcatheter resection devices were tested in a series of native porcine $(n=30)$ and reassembled calcified human valves $(n=54)$. The resection time, the resected valve area, the number of released cusps, and the degree of surrounding tissue damage were measured. Afterwards, postmortem transapical-transcatheter-resections of the aortic valve in two humans were performed.

Results: In the native porcine hearts, the Aesculap II device demonstrated significantly shorter resection time compared to the R\&R II and the Randstad devices (6.5 \pm 2.0 vs. $28.6 \pm 24.1$ vs. $23.3 \pm 14.4$ sec; $\mathrm{P}=0.001)$. However, it created more lesions in the surrounding tissue $(\mathrm{P}=0.002)$. The $\mathrm{R} \& \mathrm{R}$ II achieved a smaller number of resected cusps than the other two devices $(2.7 \pm 0.7$ vs. $1.1 \pm 0.7$ vs. $2.4 \pm 0.5 ; \mathrm{P}<0.001$, respectively). It also resected a smaller area of the aortic valve $(306.5 \pm 149.2$ vs. $106.7 \pm 29.6$ vs. $256.8 \pm 81.3 \mathrm{~mm} 2 ; \mathrm{P}=0.09)$ but a larger mean area of the resected fragments $(110.3 \pm 41.5$ vs. $160.7 \pm 29.6$ vs. $111.5 \pm 43.9 \mathrm{~mm} 2 ; \mathrm{P}=0.01)$. The resection of the reassembled human valves demonstrated the same results between the devices regarding resection time $(\mathrm{P}=0.001)$ and resected area $(\mathrm{P}=0.016)$, but not fragment sizes $(\mathrm{P}=0.610)$. Finally, transapicaltranscatheter-resection of aortic valve was performed in two cadavers.
\end{abstract}

Conclusions: Transcatheter aortic valve resection is feasible with variable aortic leaflet resection times and mild risk of lesions of the surrounding tissue.

Keywords: Transcatheter aortic valve implantation (TAVI); transcatheter; aortic valve; resection; mechanical resection

Submitted May 26, 2020. Accepted for publication Sep 09, 2020.

doi: $10.21037 /$ jtd-20-2036

View this article at: http://dx.doi.org/10.21037/jtd-20-2036

\section{Introduction}

Paravalvular leakage (PVL) is the most frequent complication after the transcatheter aortic valve implantation (TAVI) procedure and influences its longterm outcome $(1,2)$. At present, all TAVI procedures are conducted without resecting the native aortic valves not even the highly calcified cusps. The native calcified valves may restrict the expansion and deployment of the TAVI prosthesis, resulting in an irregularity of the stent frame and elevating the risk of PVL after TAVI $(3,4)$. The severity of 
valvular calcification is known to be associated with PVL. This pertains to both self-expandable $(3,5)$ and balloonexpandable (6) prostheses. Particularly, in cases with highly calcified aortic valves and a device landing zone (DLZ), the heart team always has to make a tough choice between accepting the residual PVL caused by the bulky calcified cusps or risking DLZ rupture by re-expanding the stent $(7,8)$. The calcificated aortic valve is also considered to be a factor for cerebral thrombo-emboli and stroke during TAVI procedures, leading to disastrous clinical courses for affected patients $(9,10)$.

Furthermore, it has been demonstrated that TAVI in patients with a bicuspid aortic valve has a higher incidence of PVL than in patients with a tricuspid aortic valve (11). Indeed, it probably gives a suboptimal result according to long-term efficacy (12). The cases with a unicuspid aortic valve have even been excluded from TAVI indications so far $(12,13)$.

To optimize the TAVI method and improve it to the level of a controlled surgical aortic valve replacement (sAVR), it is first necessary to remove the calcified or deformed valves before a subsequent implantation of the valved stent $(14,15)$. The feasibility of several methods of transcatheter aortic valve resection has already been demonstrated by our group (16-19).

The aim of the present study was to test the advanced ablation devices with different mechanical resection properties on native porcine (close to the human anatomy) and calcified human aortic valves in vitro. In addition, the best of the three transcatheter ablation devices was tested in two human cadavers as a proof of principle.

We present the following article in accordance with the ARRIVE reporting checklist (available at http://dx.doi. org/10.21037/jtd-20-2036).

\section{Methods}

\section{Human calcified aortic valves and porcine valves}

The study was conducted in accordance with the Declaration of Helsinki (as revised in 2013). After approval by the Ethical Committee of the Christian-AlbrechtsUniversity of Kiel (24th of November 2004; D 434/04), informed consent was taken from all the patients. Highly calcified native human aortic leaflets were taken from the operation room after routine sAVR from Nov. 2017 until July 2019. Only highly calcified cusps were selected for these experiments. In addition, thirty porcine valve resection studies were conducted in female porcine hearts German landrace which were taken from the slaughterhouse (Aesculap II group: $\mathrm{n}=10$, weight $=481.0 \pm 65 \mathrm{~g}$; R\&R II group: $\mathrm{n}=10$, weight $=473.9 \pm 57.8 \mathrm{~g}$; Randstad group: $\mathrm{n}=10$, weight $=432.5 \pm 73.5 \mathrm{~g}$ ). All experiments were conducted in the lab of the Department of Experimental Heart Surgery and Valve Replacement, University of Kiel, Germany.

\section{Resection devices}

\section{Aesculap II}

The cutting section of the Aesculap II aortic valve device (Aesculap AG, Tuttlingen, Germany) contains a mobile distal element and a fixed tubular proximal element (Figure 1). The distal element tilts to the side when the handle is released. But it can be returned to center when the handle is tightly grasped. The sharp round rims of the two parts are then pushed together and closed like a sluice knife to cut the valves, which are caught in the chamber between the two elements. A cutting section with the diameter of $43 \mathrm{Fr}$ was used in these experiments.

\section{$\mathbf{R} \& \mathbf{R}$ II}

The R\&R II punching aortic valve device (produced by Rainer Trapp Medizintechnik GmbH, Graben-Neudorf, Germany) has a double tubular casing structure. There is an opened-mouth-like cap with a sharp upper rim on the inner tube. After catching the valve in the "mouth" it can be pulled down to cut the valve off by closing its teeth-like upper rim (the sharp rim) into the outer tube (Figure 2). The diameter of the punch head is $36 \mathrm{Fr}$.

\section{Randstad}

The Randstad punch device (Randstad Deutschland GmbH \& Co. KG, Eschborn, Germany) has a similar resection principle to the Aesculap II (see above). Nevertheless, its distal conical punch head is fixed in the central position. In addition, the $38 \mathrm{Fr}$ wide device allows a guide wire or an endoscope to be advanced through an integrated lumen (Figure 3). This device has been computer designed by our group in cooperation with Randstad Inc.

\section{Experimental setup}

\section{Resection experiments on porcine aortic valves}

The resection of the native porcine aortic valve was conducted transapically: each heart underwent only one punch resection in order to simulate human procedure. 

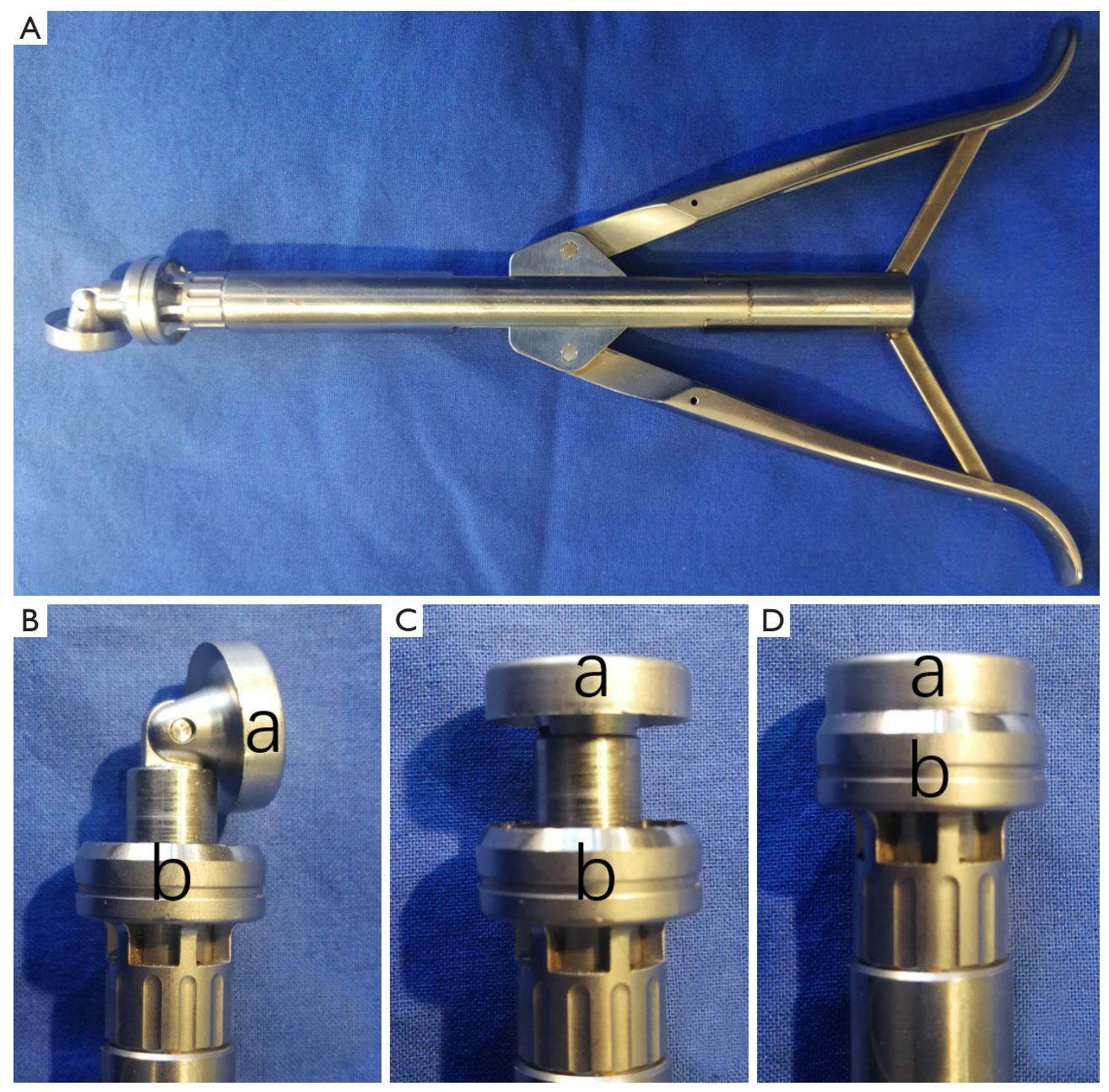

Figure 1 The Aesulap II punch device resected the calcified aortic valves in the shortest amount of time in porcine $(\mathrm{P}<0.001)$ as well as in human experiments $(\mathrm{P}<0.001)$. However, it created more lesions compared to others $(\mathrm{P}=0.002)$. (A) Overall view of device with handle; (B) released resection head; (C) the distal element of device was re-clenched; (D) the resection chamber is closed. a: the mobile distal element with circular bald; b: the fixed proximal element.

After the one punch resection, the areas of both the entire native aortic valve and resected aortic valve parts were measured. The aortic root and the surrounding structures were inspected to detect lesions caused by the resection (Figure 4). The lesions were classified into 4 grades according to the degree of the damage (0: no damage; 1 : damage on the aortic annulus; 2: non-perforative damage on the surrounding structures; 3 : perforative damage on the surrounding structures). The resection time was measured from the start of insertion of the resection device through the ventricle into the valve until its complete retrieval from the ventricle (non-blinded study by two investigators).

\section{Resection experiments on assembled calcified human aortic valves}

In the preliminary experiments $(n=54)$ a diameter of $24.0 \mathrm{~mm}(72 \mathrm{Fr})$ was determined for the flange used, as it corresponds approximately to the mean value of the aortic annulus diameter in men and women (20). The initial surface area and the resected area were quantified by using ImageJ software (National Institutes of Health, USA; see Figure 5).

\section{Resection experiments in two human cadavers}

The best transcatheter ablation device (the Randstad punch device, designed by our group) was used to perform 

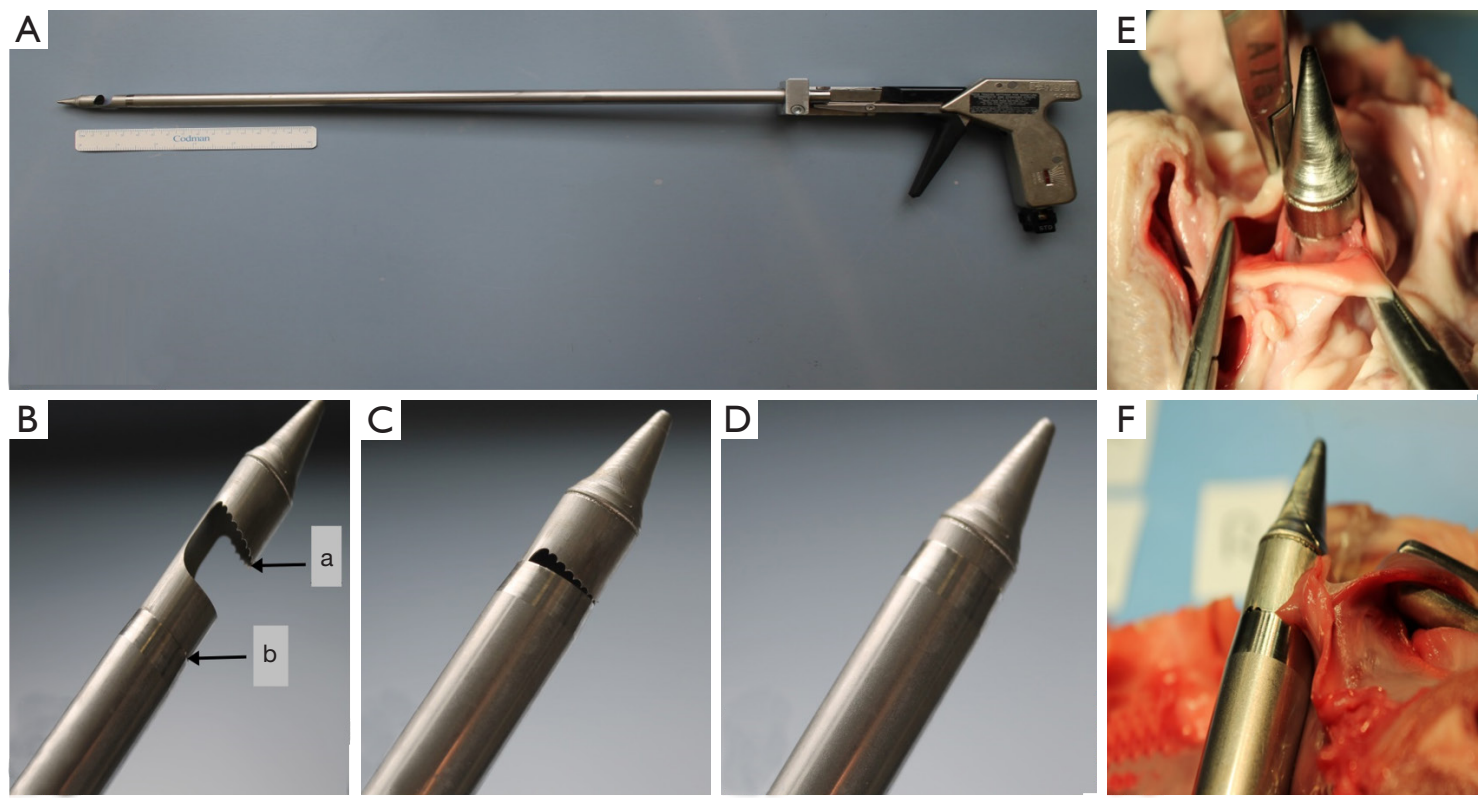

Figure 2 The R\&R II resection device resected a smaller number of cusps than the other two devices $(\mathrm{P}<0.001)$. The latter also resected with $158.4 \pm 66.1 \mathrm{~mm}^{2}$ a smaller area of the aortic valve $(\mathrm{P}=0.016)$. (A) overall view of device with pistol handle; (B) opened resection chamber (a: upper metal teeth blade of the resection chamber; b: lower cutting edge of the outer tube); (C) the inner tube is pulled down by moving the handle together; (D) closed chamber; (E,F) top view and lateral view of a captured aortic cusp.
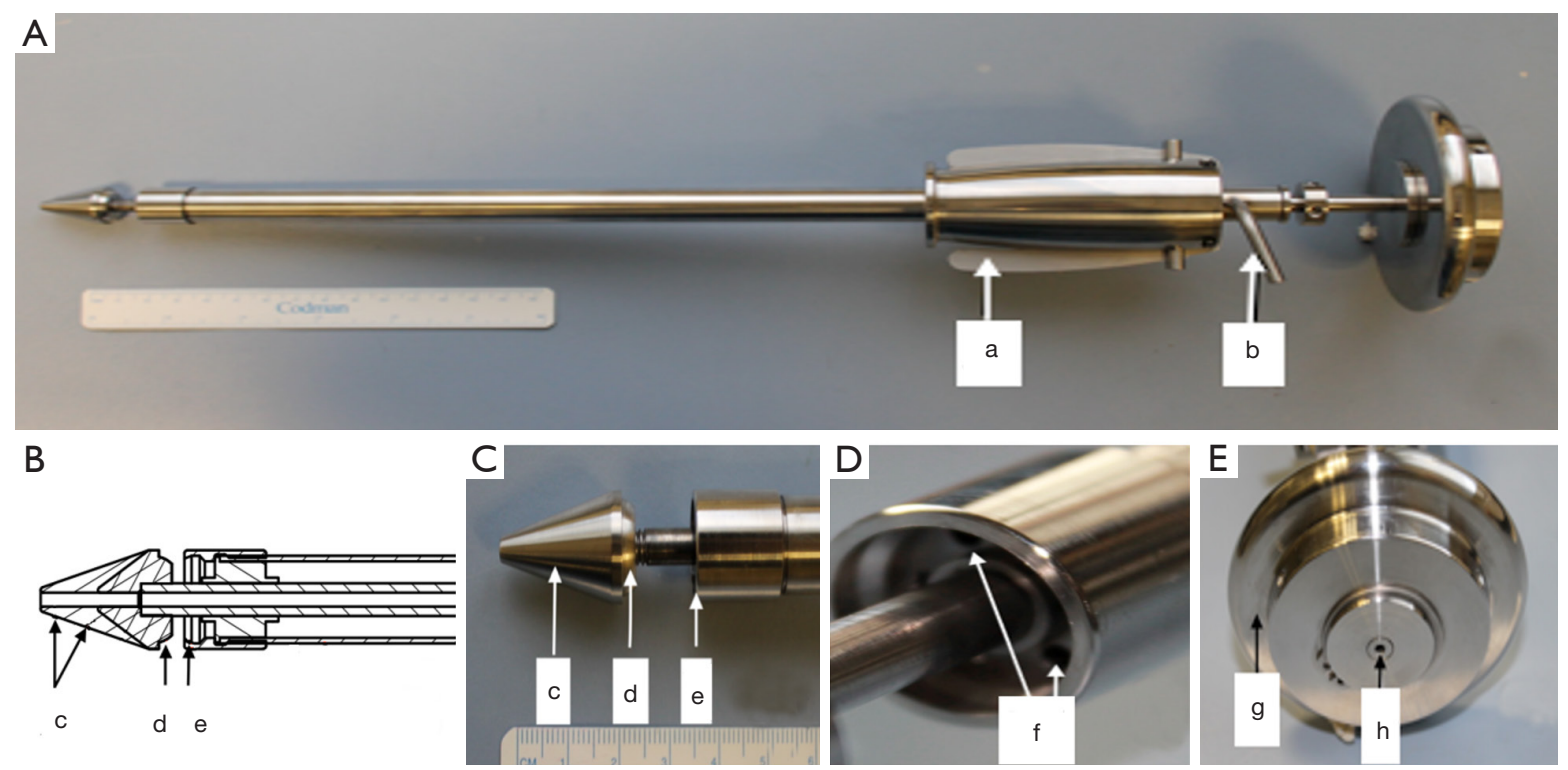

Figure 3 The Randstad punch (A, designed by our group) removed the second largest amount of tissue with $250.9 \pm 92.7 \mathrm{~mm}^{2}$ in human studies $(\mathrm{P}<0.016)$ and created no damage in porcine studies (a: locking handle; b: connector for suction unit). (B,C,D) Punch resection head of the Randstad (c: punching cone; d: rounded abutment; e: external tube with integrated cutting edge; f: resection chamber of punching head); (E) the control handle (g: inlet for suction unit; h: the guide wire lumen). 

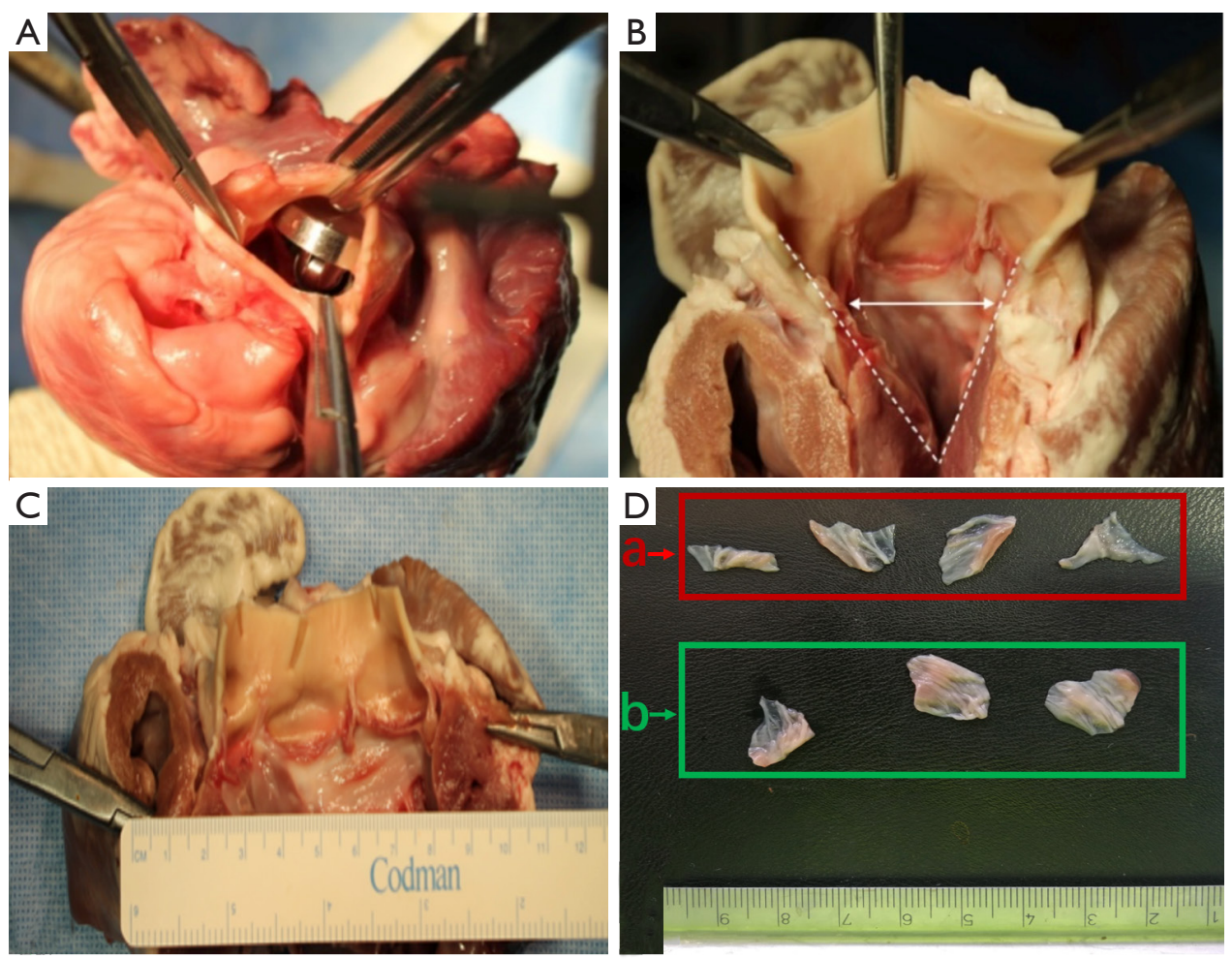

Figure 4 Resection process and analysis of the native porcine aortic valve thereafter. (A) Transapical passage through the cusps with the device, positioning above aortic valve; (B) after sagittal dissection of the heart, view on resected aortic valve; (C,D) porcine heart after resection (a: not resected residual parts of the aortic cusps; b: resected aortic cusps).

a postmortem single punch resection of the aortic valve in two human cadavers. After a 2 -inch incision, the $7^{\text {th }}$ intercostal space was dissected for an efficient transapical approach, followed by insertion of the Randstad ablation device (the latest development compared to the other two evaluated resection devices), advancement of this device into the ascending aorta and finally resection of the mildly calcified aortic valve in a single punch technique. The entire procedure was guided by an endoscope (Video 1). Time duration of the procedure (resection time, see above), number of cusps, entireness of cusps, and the lesions which might have occurred ( 0 : no damage; 1 : damage on the aortic annulus; 2: non-perforative damage on the surrounding structures; 3 : perforative damage on the surrounding structures) were monitored.

\section{Statistical analysis}

All statistical analyses were performed using the statistical software package SPSS (IBM SPSS Statistics for Windows,
Version 23; IBM Corp., Armonk, NY, USA) and R (Version 3.6.2). Since the normal distribution assumption was for the continuous data not violated (Shapiro-Wilk test), these data were reported by mean with standard deviation (SD) and analysed by variance analysis (ANOVA) followed by multiple comparions tests (Sheffé). Further, the lesions grade was analyzed using the Fisher-test for categorical parameters. The probability of a type I error was set to $5 \%(\alpha=0.05)$.

\section{Results}

\section{Resection of porcine aortic valves}

All devices were positioned into the aortic annulus without difficulties. Afterwards, resection of the aortic valve was successfully completed in all cases.

The Aesculap II device demonstrated significantly shorter resection time compared to the R\&R II and the Randstad devices $(6.5 \pm 2.0$ vs. $28.6 \pm 24.1$ vs. $23.3 \pm 14.4$ sec; $\mathrm{P}=0.001)$. There was no significant difference in resection 

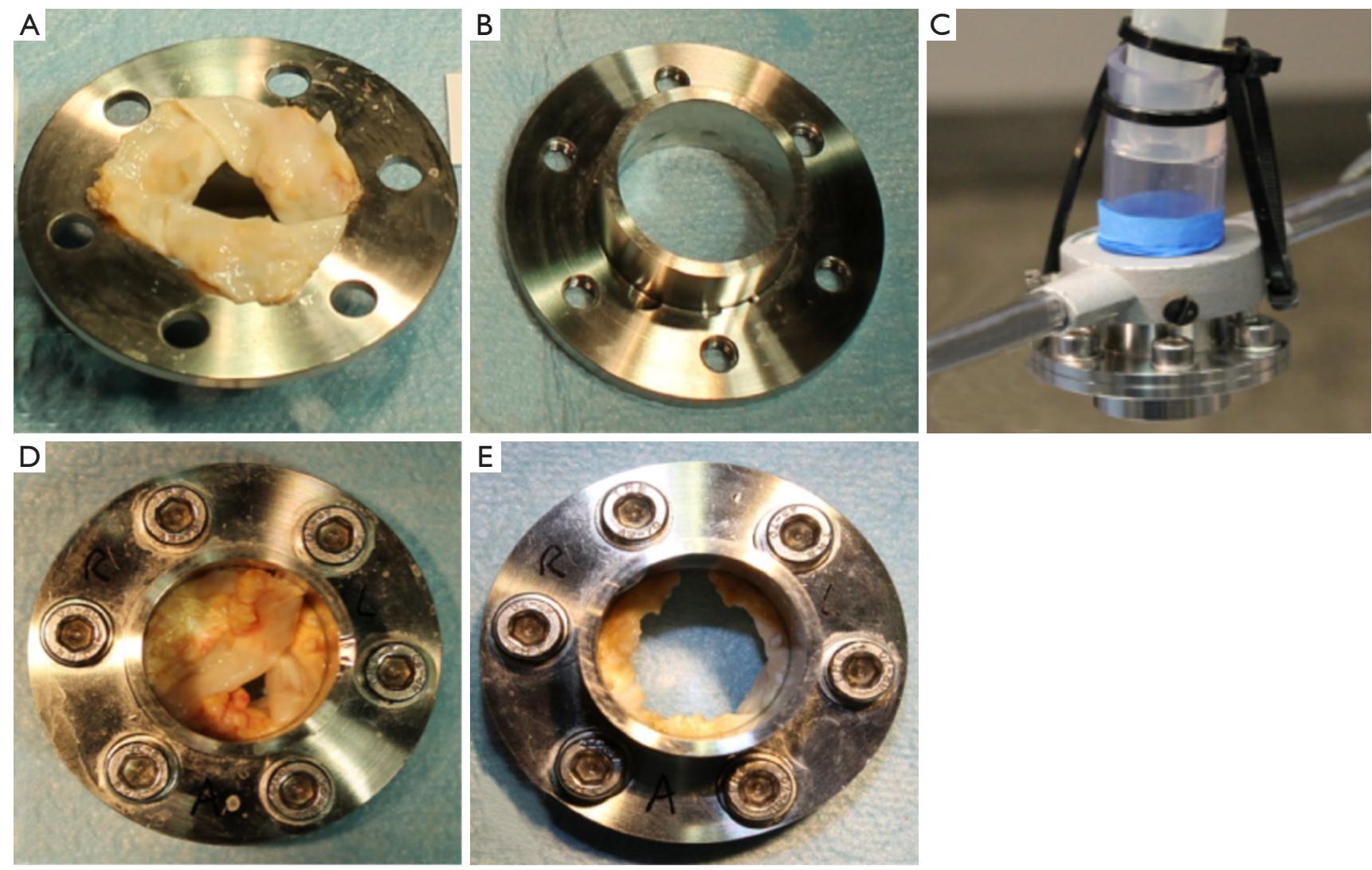

Figure 5 Experimental setup with a custom-made metal flange designed to allow an optimal fixation of the calcified valves before resection experiments. (A) Upper part of the flange with cusps in place; (B) lower part; (C) assembled calcified human aortic valve chamber with a device delivery tube; (D) pre-resection view of the flange in supravalvular direction; (E) post-resection view of the flange in supravalvular direction.

time between the other two devices $(\mathrm{P}=0.85)$.

The R\&R II aortic resection device resected a smaller number of cusps than the other two devices $(2.7 \pm 0.7$ vs. $1.1 \pm 0.7$ vs. $2.4 \pm 0.5 ; \mathrm{P}<0.001)$. Furthermore, it also resected a smaller area of the aortic valve $(306.5 \pm 149.2 \mathrm{vs}$. $106.7 \pm 29.6$ vs. $\left.256.8 \pm 81.3 \mathrm{~mm}^{2} ; \mathrm{P}=0.09\right)$. No differences in the number of resected cusps and resected area were seen between the Aesulap II and the Randstad resection devices (number of resected cusps: $\mathrm{P}=0.28$; resected area: $\mathrm{P}=0.39$ ). Additionally, the $\mathrm{R} \& \mathrm{R}$ II resection device ablated $69.6 \% \pm 9.7 \%$ of the area of the captured cusps. Besides, it cut resected fragments with a larger mean area $(110.3 \pm 41.5$ vs. $160.7 \pm 29.6$ vs. $\left.111.5 \pm 43.9 \mathrm{~mm}^{2} ; \mathrm{P}=0.01\right)$. The ratio of the resected area and the resection chamber area of the Aesculap II ablation device was lower than that of the other two devices $(89 \% \pm 43 \%$ vs. $142 \% \pm 26 \%$ vs. $145 \% \pm 46 \%$; $\mathrm{P}=0.015$ ) (Table 1, Figure 6).
Injuries to peripheral structures occurred in $6 / 10$ experiments with the Aesulap II, 5 of which were critically perforative damage and the other marginal on the aortic root (Figure 7). In contrast, the R\&R II resection device caused only one lesion on the aortic annulus (1/10). No damage was created by the Randstad resection device $(0 / 10)$. Thus, the Aesulap II had the lowest security of the three devices $(\mathrm{P}=0.002)$ while the others showed no significant difference to one another $(\mathrm{P}=0.74)$.

\section{Resection of assembled calcified human aortic valves}

The Aesculap II resected as already shown in the porcine aortic valves also the human calcified aortic valves in the shortest amount of time (Aesculap II $17.1 \pm 3.9 \mathrm{sec}, \mathrm{R} \& \mathrm{R}$ $41.8 \pm 11.1 \mathrm{sec}$, Randstadt $35.4 \pm 9.1 \mathrm{sec} ; \mathrm{P}<0.001)$. However, the Aeculap II device removed the largest amount of tissue area 
Table 1 Inter-group comparison of native porcine aortic valve resection experiments

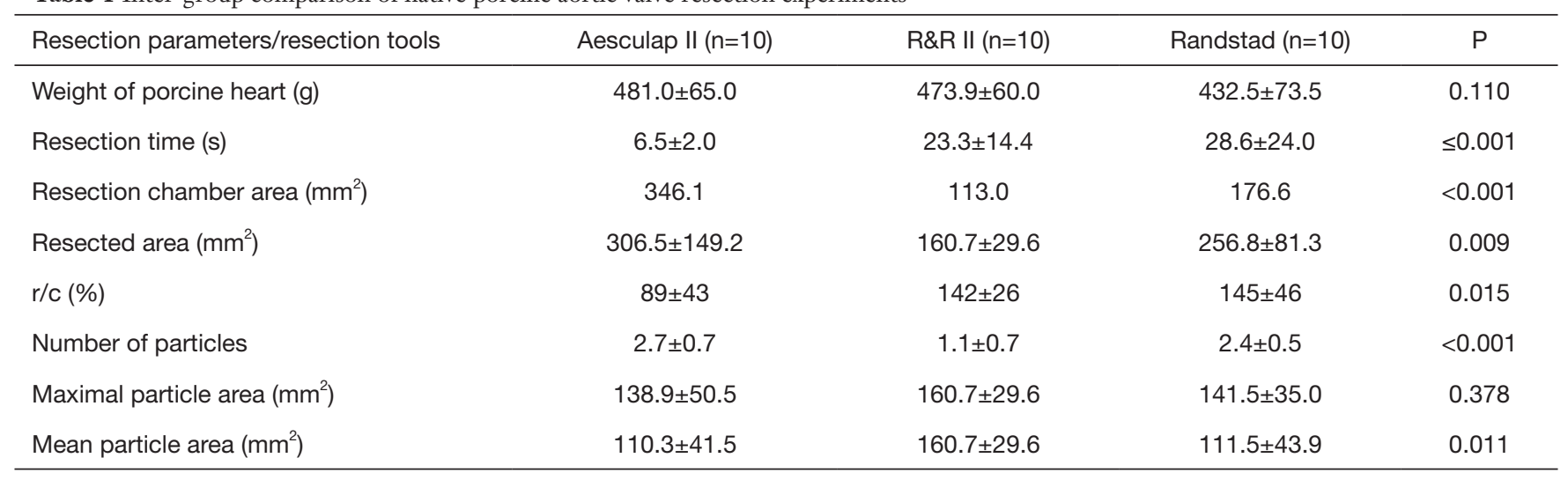

Aesculap II, R\&R II and Randstad are the names of various resection tools. r/c, resected area/resection chamber area.

with $260.9 \pm 82.0 \mathrm{~mm}^{2}$, the R\&R II device $158.4 \pm 66.1 \mathrm{~mm}^{2}$ and the Randstad punch device $250.9 \pm 92.7 \mathrm{~mm}^{2}$ ( $\left.\mathrm{P}=0.016\right)$.

Though there was no statistical significance between the three resection groups $(\mathrm{P}=0.61)$, analysis of the removed tissue fragments showed that the resected fewest large particles were released by the Aesculap II, with a median average of $1(0.3-2.8)$ resected large fragment per 18 tests. These fragments had a mean diameter of $3.1 \pm 1.5 \mathrm{~mm}$. The Randstad punch released a median of 1.5 (0.0-3.8) large particles per 18 attempts with a mean diameter of $3.1 \pm 1.4 \mathrm{~mm}$, while the R\&R II had the largest median number of tissue fragments $3(0.3-4.0)$. The mean particle diameter in these cases was $3.4 \pm 2.2 \mathrm{~mm}$.

\section{Resection experiments in two buman cadavers}

The Randstadt device was transapically tested as a proof of concept study in two human cadavers: the time duration of the procedures was $11.2 \pm 2.3 \mathrm{sec}$., all three aortic valve cusps were entirely resected in the two human aortas, and video monitoring showed no lesions in the area of ablation in the aorta, LVOT, and left ventricle.

\section{Discussion}

In our proof of concept study, we compared three different mechanical aortic valve resection devices with different ablation properties to transapically resect the native aortic valve before the TAVI. Major findings in our analysis are, that the Aesculap II ablation device resectioned the aortic valve in both groups much faster compared to the other resection devices, but caused significantly more damage to the surrounding tissue. This is probably due to its more efficient handling mechanism and its stronger and sharper and larger edge cutting system. The size of the resection area was also a critical factor. Furthermore, in our studies on assembled calcified human aortic valves we demonstrated the feasibility of transcatheter resection of highly calcified aortic valves by using modified transcatheter aortic valve devices. The cutting procedure was efficiently conducted in a short time period. This was also confirmed in the two successful cadaver studies, in which all entire three aortic leaflets were resected in a short time period.

Wendt and colleagues showed in seven artificial stenosed porcine aortic valves that they were able to resect them without any major lesions. In contrast, we used human assembled calcified valves and observed with our mechanical resection tool slightly more annular lesions. This might be due to the faster one punch resection method of our group compared to the linear motor ablation and motion controller used by Wendt and coworkers (21).

In these experiments on porcine aortic valves the resection punch was only performed once on each heart. The "one punch resection" was considered to be the most likely method to be realized later clinically. In these studies, the Aesculap II resection device had the advantage of a very short resection time. However, inspection of the residual aortic valve margins and the adjacent tissue showed that compared to the other two ablation tools, the Aesculap resection device created more lesions, i.e., especially on the aortic wall. This is due to its very large resection head and was probably the major cause of damage to the surrounding tissue. Many working groups therefore used smaller resection tools, accepting lower orifice areas after transcatheter resection. But it is obvious, that the size of the punch-hat can be slightly changed in the next series of 
Overall test: $\mathrm{P}=0.01$

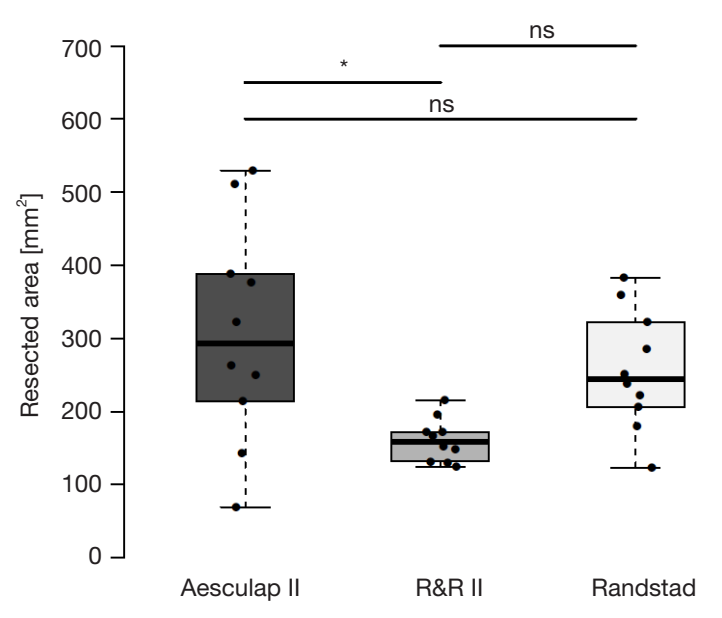

Overall test: $P=0.415$ (not significant)

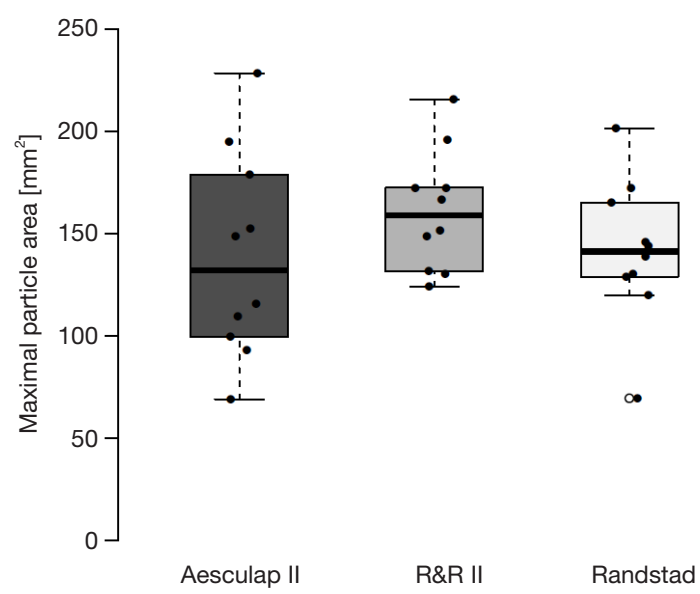

Overall test: $\mathrm{P}=0.005$

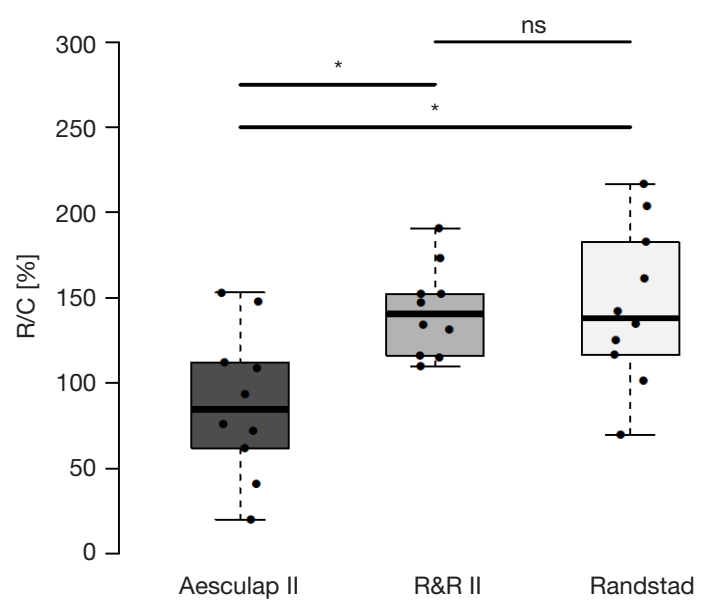

Overall test: $P=0.01$

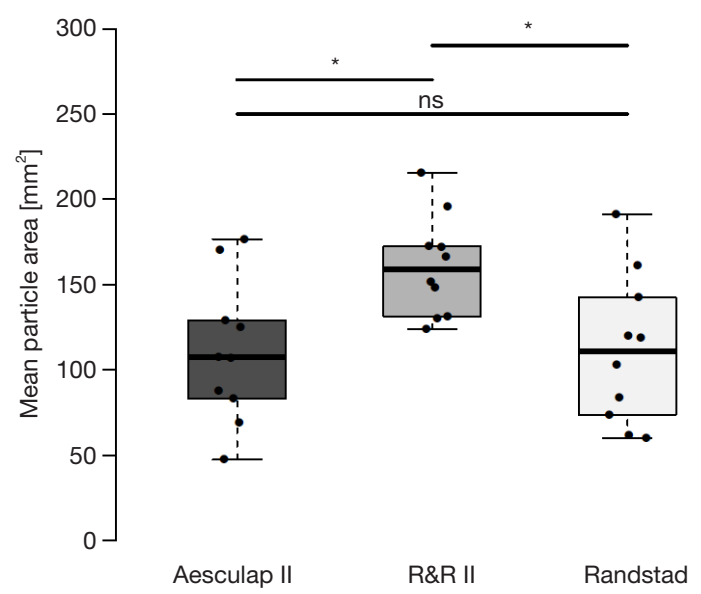

Figure 6 Inter-group analysis of all three devices (Aesculap II, R\&R II and Randstad) of porcine native aortic valve resection experiments (r/ c: resected area/resection chamber area). Differences between devices are indicated $\left({ }^{*} \mathrm{P}<0.005\right)$.

aortic valve resection experiments. Nevertheless, there is an additional deficit of this device. As mentioned before, the distal resection part of the Aesculap II device is mobile which gives a higher flexibility to insert the device into the aortic valve. This is an innovative technique not yet described. Such a movable structure reduces the crosssection area of the top of this punching device, and allows for a smoother passage through the aortic annulus. But the tilted distal part and its sharp edge could easily catch on and cut the surrounding tissue when pulled down like an upper jaw with incisor teeth. For safety reasons the distal part of the Aesculap II device should be modified for the next generation of ablation devices.

The good safety of the R\&R and the Randstad aortic ablation devices were demonstrated in this study: compared to the totally opened punch structure of the other two devices, the smaller opening of the R\&R II resection device allowed only one-cusp-resection for each punch. Therefore, the number of removed cusps was significantly different compared to the R\&R II resection group and the other two ablation groups. Nevertheless, it resected nearly $70 \%$ of the area of the captured cusp. The largest mean area of 

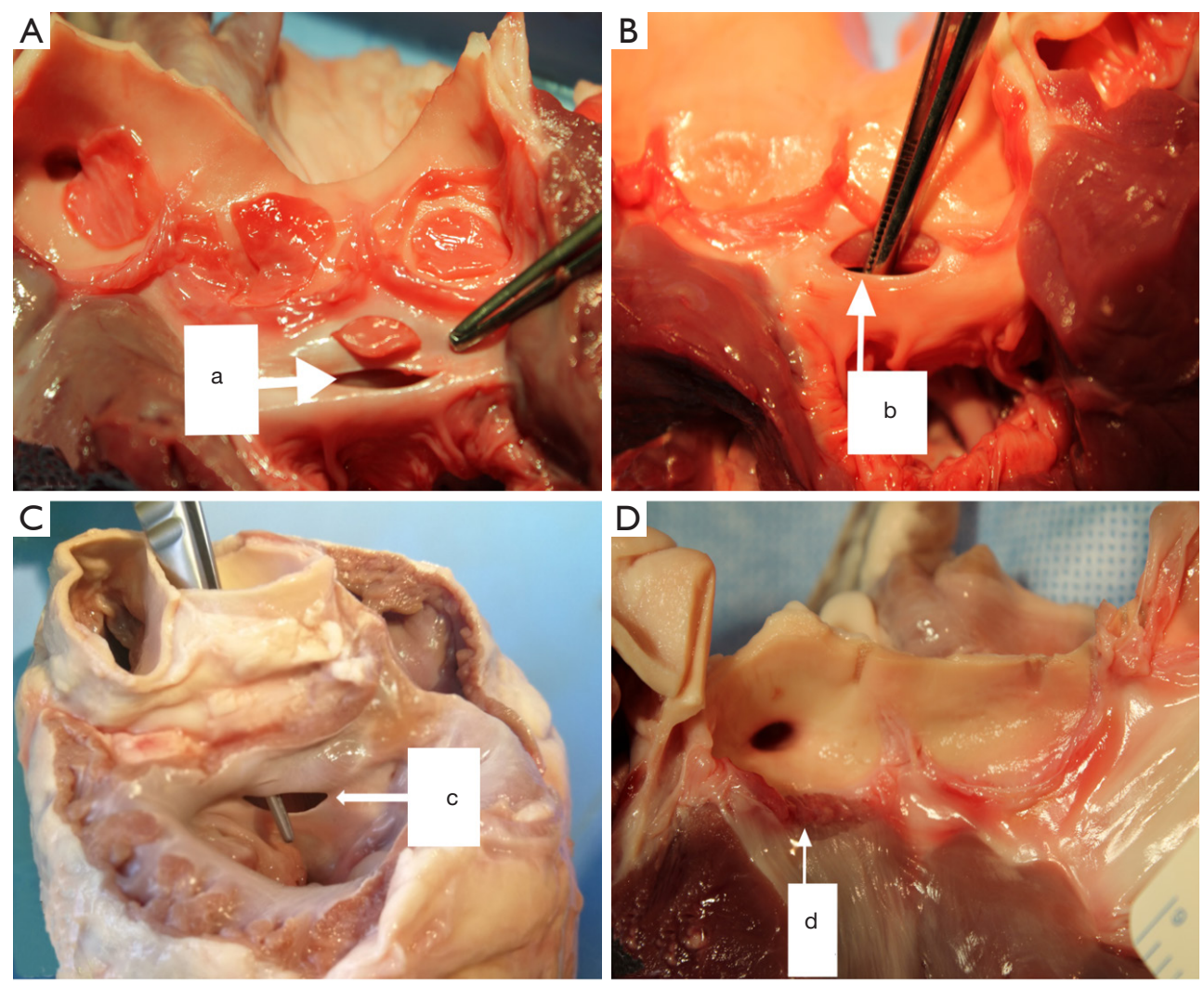

Figure 7 Lesions caused by various resection devices. (A,B,C) By the Aesculap II device (a: anterior mitral leaflet, b: interventricular septum, c: left ventricular outflow tract); (D) damage at the aortic annulus (d) caused by R\&R II device.

the resected cusps indicated that in the cases with only one highly calcified aortic cusp, the R\&R II resection device is a safe and efficient option for resecting calcified aortic valves.

A significant difference in the total resected area was also shown between the R\&R II group and the other two ablation groups. However, there was no significant difference between the Aesculap II and the Randstad resection device. The totally opened structure was probably a critical factor for more aortic cusps capture. The crosssection area of the punch resection chamber was also a factor for more resected area. The R\&R II device had the smallest resection chamber and the longest ablation time.

It was observed that the ratio of the resected area and the resection chamber area of the Aesculap II was lower than that of the other two devices. But there was no significant difference between the R\&R II group and the Randstad group. It can be suggested that the R\&R II and the Randstad ablation devices can catch and cut off more aortic valve area with the same size of their resection chamber. In this respect, the R\&R II and the Randstad ablation tool are more efficient.

Next to mechanical resection of the aortic valve, in a previous study of our research group we tested transcatheter aortic valve resection by using the Hydroscalpel and thulium-YAG laser $(17,22)$. The resection procedure times for these two devices were $6.0 \pm 2.4$ and $6.0 \pm 3.6 \mathrm{~min}$, respectively. The two novel systems were demonstrated to be safe. But so far, their lengthy operation times have hindered further development and application of these technologies for TAVI procedures.

Nevertheless, the development of two mechanical resection systems accelerated the development of transcatheter aortic valve resection technology in Europe $(23,24)$. Astarci et al. and the group of Wendt developed two different prototypes of mechanical transcatheter resection systems with circular metal blades to capture and cut the calcified aortic valves in 1 minute. These circular resection devices generated a large orifice and a calcified ring in the aortic root for anchoring the valved TAVI stents. Thus, the compromise between a secure valved stent fixation and 
an optimal orifice area can be achieved with this puncture method. Furthermore, optimal alignment of the valved stent to the surrounding structures appears to be possible based on the congruent ringlike geometry of both of the resection tools (15). Since most TAVI valves need a scaffolding of aortic stenosis for implantation, new valved stents will be developed for resected annuli (as for aortic insufficiency).

The present study demonstrated that the R\&R II aortic resection device, a modified Aesculap II ablation tool, and the newly developed Randstad punch are able to reach the aortic valve reliably via the transapical access route and to resect it successfully in the porcine heart with a minimum procedure duration of $13.7 \pm 3.1 \mathrm{~s}$ at best. In the experiments on the flange with human calcified specimens it was possible to resect large calcified parts of the aortic valve adequately and efficiently with these mechanical transcatheter aortic valve resection devices. For the other two devices a reduction of the resection time would be possible after modification of their handling systems and sections pertaining to the resection area.

\section{Limitations and future research}

In the present study, all experiments were performed on healthy porcine hearts, assembled calcified human aortic valves, and mildly calcified aortic valves in cadavers. Certainly, the cadaveric aortic valves should have been more stenosed. Therefore, in a more calcified subsequent model a special resection chamber described by Bombien and colleagues should be implemented to collect debris and to avoid any neurological event (16). Even though calcific nodules are reduced by the transcatheter resection technology it has to be proven that this technique reduces PVL rates after TAVI. Moreover, due to the overall size limitations, only one size of each device was tested in this study.

Furthermore, the transfemoral route for aortic resection might be more favorable. Therefore, transfemoral mechanical resection of the valve should be developed. Further, in situ animal tests are necessary for further evaluation of the security and efficiency of the devices under beating heart conditions. This will minimize the incidence of any potential structural damage in humans.

\section{Conclusions}

In the present study, the feasibility and efficiency of mechanical transcatheter aortic valve resection devices were demonstrated in native porcine and in calcified human aortic valves. In addition, a transapical use of the best ablation tool in cadavers revealed very good results in resecting aortic valves in situ. These experiments emphasize, that aortic valve resection prior to TAVI is possible to reduce some relevant side effects associated with TAVI in the near future.

\section{Acknowledgments}

We especially thank Daniel Schilling, for his helpful work during the experiments.

Funding: We are grateful for a company independent research grant for our project on transapical aortic valve resection by the the DZHK funding (German Center for Cardiovascular Research) (https://dzhk.de/en/the-dzhk/ about-us/mission).

\section{Footnote}

Reporting Checklist: The authors have completed the ARRIVE reporting checklist. Available at http://dx.doi. org/10.21037/jtd-20-2036

Data Sharing Statement: Available at http://dx.doi. org/10.21037/jtd-20-2036

Conflicts of Interest: All authors have completed the ICMJE uniform disclosure form (available at http:// dx.doi.org/10.21037/jtd-20-2036). JS reports grants and personal fees from Edwards, grants, and personal fees from Medtronic, outside the submitted work; DF reports personal fees from Edwards, personal fees from Medtronic, outside the submitted work; GL reports personal fees from Edwards, personal fees from Medtronic, personal fees from Abbot, outside the submitted work. The authors have no other conflicts of interests.

Ethical Statement: The authors are accountable for all aspects of the work in ensuring that questions related to the accuracy or integrity of any part of the work are appropriately investigated and resolved. The study was conducted in accordance with the Declaration of Helsinki (as revised in 2013). After approval by the Ethical Committee of the Christian-Albrechts-University of Kiel (24th of November 2004; D 434/04), informed consent was taken from all the patients.

Open Access Statement: This is an Open Access article 
distributed in accordance with the Creative Commons Attribution-NonCommercial-NoDerivs 4.0 International License (CC BY-NC-ND 4.0), which permits the noncommercial replication and distribution of the article with the strict proviso that no changes or edits are made and the original work is properly cited (including links to both the formal publication through the relevant DOI and the license). See: https://creativecommons.org/licenses/by-nc-nd/4.0/.

\section{References}

1. Kodali SK, Williams MR, Smith CR, et al. Two-year outcomes after transcatheter or surgical aortic-valve replacement. N Engl J Med 2012;366:1686-95.

2. Athappan G, Patvardhan E, Tuzcu EM, et al. Incidence, predictors, and outcomes of aortic regurgitation after transcatheter aortic valve replacement: meta-analysis and systematic review of literature. J Am Coll Cardiol 2013;61:1585-95.

3. Di Martino LFM, Soliman OII, van Gils L, et al. Relation between calcium burden, echocardiographic stent frame eccentricity and paravalvular leakage after corevalve transcatheter aortic valve implantation. Eur Heart J Cardiovasc Imaging 2017;18:648-53.

4. Delgado V, Kapadia S, Schalij MJ, et al. Transcatheter aortic valve implantation: implications of multimodality imaging in patient selection, procedural guidance, and outcomes. Heart 2012;98:743-54.

5. Leber AW, Kasel M, Ischinger T, et al. Aortic valve calcium score as a predictor for outcome after TAVI using the CoreValve revalving system. Int J Cardiol 2013;166:652-7.

6. Delgado V, Ng AC, van de Veire NR, et al. Transcatheter aortic valve implantation: role of multi-detector row computed tomography to evaluate prosthesis positioning and deployment in relation to valve function. Eur Heart J 2010;31:1114-23.

7. Buellesfeld L, Stortecky S, Heg D, et al. Extent and distribution of calcification of both the aortic annulus and the lleft ventricularoutflow tract predict aortic regurgitation after transcatheter aortic valve replacement. EuroIntervention 2014;10:732-8.

8. Hansson NC, Norgaard BL, Barbanti M, et al. The impact of calcium volume and distribution in aortic root injury related to balloon-expandable transcatheter aortic valve replacement. J Cardiovasc Comput Tomogr 2015;9:382-92.

9. Aggarwal SK, Delahunty RN, Menezes LJ, et al. Patterns of solid particle embolization during transcatheter aortic valve implantation and correlation with aortic valve calcification. J Interv Cardiol 2018;31:648-54.

10. Kahlert P, Al-Rashid F, Dottger P, et al. Cerebral embolization during transcatheter aortic valve implantation: a transcranial Doppler study. Circulation 2012;126:1245-55.

11. Takagi H, Hari Y, Kawai N, et al. Meta-analysis of transcatheter aortic valve implantation for bicuspid versus tricuspid aortic valves. J Cardiol 2019;74:40-8.

12. Mylotte D, Lefevre T, Sondergaard L, et al. Transcatheter aortic valve replacement in bicuspid aortic valve disease. $\mathrm{J}$ Am Coll Cardiol 2014;64:2330-9.

13. Jones BM, Krishnaswamy A, Tuzcu EM, et al. Matching patients with the ever-expanding range of TAVI devices. Nat Rev Cardiol 2017;14:615-26.

14. Lutter G, Ardehali R, Cremer J, et al. Percutaneous valve replacement: current state and future prospects. Ann Thorac Surg 2004;78:2199-206.

15. Attmann T, Bombien R, Cremer J, et al. eComment. transcatheter aortic valve implantation: need for continuing experimental research. Interact Cardiovasc Thorac Surg 2012;14:380-1.

16. Bombien R, Humme T, Schunke M, et al. Percutaneous aortic valve replacement: computed tomography scan after valved stent implantation in human cadaver hearts. Eur J Cardiothorac Surg 2009;36:592-4.

17. Quaden R, Attmann T, Boening A, et al. Percutaneous aortic valve replacement: resection before implantation. Eur J Cardiothorac Surg 2005;27:836-40.

18. Marczynski-Bühlow M, Gro J, Berndt R, et al. Comparison of different resection tools for human calcified aortic valves. Innovations (Phila) 2014;9:312-6.

19. Rohde I, Masch JM, Theisen-Kunde D, et al. Resection of calcified aortic heart leaflets in vitro by Q-switched 2 microm microsecond laser radiation. J Card Surg 2015;30:157-62.

20. Erbel R, Alfonso F, Boileau C, et al. Diagnosis and management of aortic dissection. Eur Heart J 2001;22:1642-81.

21. Wendt D, Stühle S, Wendt H, et al. Cutting precision in a novel aortic valve resection tool. Research in progress. Interact Cardiovasc Thorac Surg 2009;9:672-6.

22. Quaden R, Attmann T, Schunke M, et al. Percutaneous aortic valve replacement: endovascular resection of human aortic valves in situ. J Thorac Cardiovasc Surg 2008;135:1081-6.

23. Astarci P, Glineur D, Elkhoury G, et al. A novel device for 
endovascular native aortic valve resection for transapical transcatheter aortic valve implantation. Interact Cardiovasc Thorac Surg 2012;14:378-80.

Cite this article as: Dai H, Lutter G, Frank D, Freitag-Wolf S, Topal A, Haneya A, Sathananthan J, Puehler T. Transcatheter aortic valve resection: new mechanical devices. J Thorac Dis 2020;12(11):6586-6597. doi: 10.21037/jtd-20-2036
24. Wendt D, Müller W, Hauck F, et al. In vitro results of a new minimally invasive aortic valve resecting tool. Eur J Cardiothorac Surg 2009;35:622-7; discussion 627. 